HOW TO CITE: Broadhead, JS, Muxworthy, AR, Ong, C.K. and Black, CR Comparison of methods for determining leaf area in tree rows, AGR FOREST METEOROL, 2003, Vol: 115, Pages: 153 - 163, ISSN: 0168-1923

4

\title{
COMPARISON OF SOME METHODS FOR DETERMINING LEAF AREA OF TREES IN ROWS
}

\section{J.S. Broadhead ${ }^{1}$, A.R. Muxworthy ${ }^{2}$, C.K. Ong ${ }^{3}$ and C.R. Black ${ }^{1}$}

${ }^{1}$ Plant Science Division, School of Biosciences, University of Nottingham, Sutton Bonington Campus, Loughborough, LE12 5RD, UK

${ }^{2}$ Department of Geology \& Geophysics, University of Edinburgh, Grant Institute, West Mains Road, Edinburgh, EH9 3JW, UK.

${ }^{3}$ International Centre for Research in Agroforestry, ICRAF House, PO Box 30677, Gigiri, Nairobi, Kenya

Running title: Measuring leaf area in tree rows 


\section{ABSTRACT}

Two methods for determining the leaf area of trees growing in rows using an LAI-2000 Plant Canopy Analyser were tested against destructive measurements for Croton

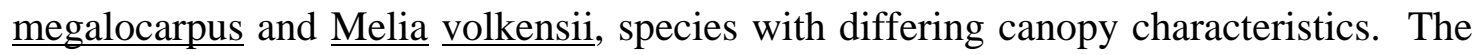
trees ranged between 4.0 and $7.5 \mathrm{~m}$ in height and formed part of an agroforestry experiment in semi-arid Kenya where rapid fluctuations in canopy cover rendered allometric approaches inappropriate for determining leaf area. The first method used unmodified theory for determining leaf area in continuous canopies which has proved suitable for isolated bushes. In the second method, path lengths through the canopy were calculated from simple measurements of canopy dimensions and the importance of subsidiary assumptions concerning leaf angle distribution was tested. Leaf angle distribution, which is required for canopy simulation models, was also determined using both direct and indirect approaches and the effect of using assumed leaf angle distributions when calculating leaf area was assessed. The canopy analyser proved unsuitable for measuring leaf angle distributions in isolated canopies, and it was necessary to make direct canopy measurements for this instrument to be used for smaller canopies. It was also shown that, even when path lengths are measured, calibration may be necessary to avoid bias; uncalibrated leaf area density estimates were, on average, underestimated by $16 \%$ for $\underline{\mathrm{M}}$. volkensii and overestimated by $8 \%$

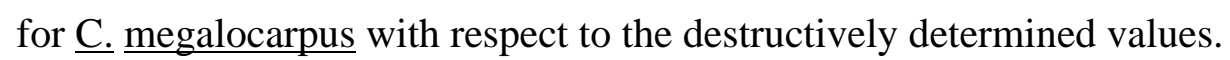

Keywords: LAI-2000, plant canopy analyser, leaf area, leaf area density, leaf angle distribution, tree rows, Croton megalocarpus, Melia volkensii, agroforestry. 
INTRODUCTION

The quantity and pattern of radiation interception by vegetation canopies, upon which plant growth and productivity ultimately depend, are related to the number and spatial distribution of individual canopy elements. In agroforestry systems, the tree canopy is important not only in influencing tree-environment interactions, but also because it modifies the microclimate experienced by associated crops (Jackson and Palmer, 1989; Tournebize and Sinoquet, 1995; Brenner, 1996) and influences soil moisture content due to effects on water uptake, transpiration and soil evaporation (Ong et al., 1991; Howard et al., 1995). Norman and Campbell (1989) suggested that descriptions of canopy structure may reveal the strategy adopted by individual species in dealing with the evolutionary process of adaptation to the prevailing physical, chemical or biotic factors by reflecting their inherent patterns of activity. The latter is of interest to agroforestry as the timing of phenological changes in relation to the prevailing environment play a determining role in tree-crop interactions (Broadhead et al., 2002b).

Canopy structure is usually quantified in terms of leaf area and the spatial and geometric organisation of individual elements within a defined canopy envelope. The problems associated with quantification generally increase with the size and temporal and spatial heterogeneity of the canopy. Norman and Campbell (1989) broadly classified the methods available for quantifying canopy structure as being either direct or indirect. Direct methods are often reliable but are usually destructive and become excessively laborious when applied to large or temporally heterogeneous canopies. However, the closeness of the coupling between radiation exchange and canopy structure often enables canopy characteristics to be inferred from radiation measurements using theory developed from the Monsi and Saeki/Beer's law equation (Monsi and Saeki, 1953; Anderson, 1966; Ross, 1975). Indirect methods may therefore be used in conjunction with assumptions concerning canopy shape and the distribution and orientation of leaves to provide more rapid assessments of leaf area. However, cases where some of the simpler assumptions are less likely to apply, e.g. where foliage is non-randomly distributed (Norman and Jarvis, 1975; Cohen et al., 
1 1995; Lang et al., 1985), or canopies are discontinuous (Jackson and Palmer, 1989;

2 Brenner et al., 1995) must be recognised and potential errors avoided by removing or

3 redefining assumptions.

4 The primary objective of the work reported here was to develop a rapid method for 5 determining canopy structural parameters for Melia volkensii and Croton 6 megalocarpus to provide input variables for canopy simulations and allow direct 7 comparisons of tree species. Attempts to develop allometric relationships between 8 branch cross-sectional area and leaf area similar to those established by previous 9 workers (Nygren et al., 1994; Lott et al., 2000) were confounded by the continual and 10 rapid fluctuation of leaf cover in $\underline{\mathrm{M}}$. volkensii and, to a lesser extent, $\underline{\mathrm{C}}$. megalocarpus 11 (Broadhead et al., 2002a, b). The physical size and height of the trees also precluded 12 direct measurement of canopy characteristics without felling them. Two indirect 13 approaches based on measurements made using an LAI-2000 canopy analyser were 14 therefore compared with a direct method for assessing leaf area.

15 A secondary objective was to determine leaf angle distributions for both species; two indirect methods using the LAI-2000 were again compared with a more laborious direct method. These measurements also allowed the error involved in the assumption of a spherical leaf angle distribution, required under certain circumstances when using the LAI-2000, to be assessed. 


\section{THEORY AND METHODS}

\section{Experimental design}

The experimental design was a randomised complete block with four replicates. The $18 \times 18$ m plots contained a central row of 19 trees (586 trees ha $\left.{ }^{-1}\right)$ planted in an eastwest orientation and were surrounded by $1 \mathrm{~m}$ wide buffer zones. To maintain the uniformity of the tree canopies in each plot branches deviating significantly from the collective canopy perimeter were pruned before the onset of the rains. Trenches dug to a depth of $2 \mathrm{~m}$ around all plots and refilled at the beginning of each cropping season were used to minimise root interference between plots. Maize (Zea mays L.) and beans (Phaseolus vulgaris L.) were grown during the long (March-July) and short rainy seasons (October-February) respectively. Full experimental details are given by Broadhead et al. (2002a).

\section{Indirect leaf area measurements}

An LAI-2000 Plant Canopy Analyser (Li-Cor Inc., Lincoln, NE, USA) was used to determine leaf areas for $\underline{\mathrm{M}}$. volkensii and $\underline{\mathrm{C}}$. megalocarpus using a standard method for horizontally continuous canopies and a modification of the isolated tree technique described by Li-Cor (1992). The instrument was originally designed to estimate the leaf area index of continuous canopies, but has been used with isolated trees with


Fownes, 1998). Its use for estimating leaf area in isolated tree rows has not previously been documented.

The LAI-2000 has a hemispherical lens and optical sensors that detect radiation at five zenith angles (Welles and Norman, 1991; Li-Cor, 1992). Gap fractions at each angle are determined from measurements of diffuse radiation made above and below the canopy (Fig. 1); inversion and numerical integration of the transmission data are used to estimate leaf area density (LAD). Measurements are made under diffuse radiation conditions as the presence of even small amounts of direct radiation may introduce substantial errors (Welles, 1990). View caps may be used to restrict the azimuthal 
1 view range of the lens if large gaps in the canopy are present or the canopy of isolated 2 plants is asymmetric. It is assumed that: 1) foliage elements are small relative to the area of view at each zenith angle; 2) foliage is randomly orientated with respect to the azimuth and randomly distributed within a defined envelope; and 3) foliage does not reflect or transmit radiation below $490 \mathrm{~nm}$ (Li-Cor, 1992).

Comparisons were made between estimates of leaf area obtained using the method for continuous canopies where path lengths were estimated as $1 / \cos \theta$ and a second method using calculated path lengths. The theory used to calculate foliage area is based on the gap fraction or contact frequency technique developed by Warren-Wilson and Reeve (1959) and described in detail by Welles and Norman (1991) and Li-Cor (1992).

$\mu=2 \int_{0}^{\pi / 2} \frac{-\ln (T(\theta))}{S(\theta)} \sin \theta d \theta$

Numerical integration over the five zenith angles gives:

22

where $K(\theta)$ is the contact frequency, or the average number of contacts per unit length that a probe would make when passed through the canopy at zenith angle $\theta$. The analytical solution for foliage density is given by Miller (1967) as:

$\mu=2 \sum_{i=1}^{5} \frac{-\ln \left(T_{i}\right)}{S_{i}} W_{i}$ 
$7 \quad \mu=2 \sum_{i=1}^{5} K_{i} W_{i}$

where $T_{\mathrm{i}}$ denotes the proportion of radiation transmitted at the five zenith angles and $W_{i}$ represents $\sin \theta_{1} \mathrm{~d} \theta_{1}$ values computed by breaking the 0 to $90^{\circ}$ interval into five unequal intervals based on the central zenith angle assigned to detector rings $1-5\left(7^{\circ}, 23^{\circ}, 38^{\circ}\right.$, $53^{\circ}, 68^{\circ}$ ) and normalising the values obtained (i.e. scaling them so their sum is equal to 1). The $\mathrm{d} \theta$ values correspond to the zenith interval covered by the detector rings. Substitution from equation 2 gives:

Method 1 for estimating leaf area entailed the use of path lengths calculated as $1 / \cos \theta$ to provide estimates of leaf area index (Welles and Norman, 1991). This approach is generally used for horizontally continuous canopies (Li-Cor, 1992), but was found by Brenner et al. (1995) to provide reliable estimates for isolated hemispherical bushes. This method assumes that path lengths are approximated by the reciprocal of the cosine of the zenith angle (ring view angle) and that the leaves are randomly distributed within the canopy and symmetrically distributed with respect to azimuth; in the present study, the canopies within individual tree rows were assumed to be homogeneous within each $1 \mathrm{~m}$ row length. To facilitate comparison with method 2, leaf area index values were converted to leaf area density using estimated canopy dimensions as detailed below.

Method 2 differed in that canopy dimensions were used to estimate path lengths, $S$, for each zenith angle. This is recommended for isolated plants in which the horizontal extent of the canopy is less than three times plant height (Li-Cor, 1992). Assumptions differed from those in Method 1 as the canopies within individual tree rows were elliptical in cross-section; path lengths could therefore be approximated from simple canopy measurements. Measurements were made using a $90^{\circ}$ view cap, with the sensor positioned centrally between adjacent trees and directed perpendicular to the tree row towards the north or south. This procedure restricted the canopy view to a volume approximated by a $90^{\circ}$ segment of an ellipsoid with semi-axis dimensions defined by direct measurements of the canopies (Fig. 1); it also decreased the number of measurements required to define the canopy perimeter. Path length $(S)$ was 
$9 \quad \frac{K_{i}}{G_{i}}=\frac{K_{i-1}}{G_{i-1}}$

calculated from this defined ellipse and the measured sensor height for each LAI-2000 measurement as detailed in Appendix 1.

Depending on the position of the sensor relative to the canopy, light received by one or more of the outer detector rings (see Fig. 1) may not actually pass through the canopy. To calculate the relevant $K_{i}$ value (see Eq. 5), foliage density ( $\mu$ ) for the ring was assumed to be equal to that calculated for the outermost ring which did receive light that had passed through the canopy; thus by substituting for $\mu$ in equation 2 , the following may be written:

The value of $K_{i}$ required to estimate canopy leaf area density (Eq. 5) can then be approximated as:

$K_{i}=\frac{G_{i}}{G_{i-1}} K_{i-1}$

where $G_{i}$ represents the fraction of foliage projected in the direction of the five zenith angles $(i)$ calculated from direct measurements of leaf angle distribution.

The inclination angles of c. 150 randomly sampled leaves from both $\underline{\mathrm{C}}$. megalocarpus and $\underline{\mathrm{M}}$. volkensii were measured to provide input for a canopy simulation model (Broadhead, 2000) and estimate $G(\theta)$ values for LAI-2000 measurements where values for outer rings were missing. Because leaves were only accessible from permanent canopy-level platforms, measurements were confined to the southern side of the canopies in Replicates 2 and 4. Measurements were made at all levels in the canopy using a protractor with a weighted dial mounted at its centre, as described by Norman and Campbell (1989).

To estimate missing LAI-2000 $K_{i}$ values, measured leaf angle distributions were used to calculate $G(\theta)$ values for zenith angles corresponding to the LAI-2000 view angles $\left(7^{\circ}, 23^{\circ}, 38^{\circ}, 53^{\circ}, 68^{\circ}\right)$. For each zenith angle, $G_{\alpha}(\theta)$, the fraction of foliage inclined at angle $\alpha$ projected in direction $\theta$ was calculated for nine leaf angle classes centred at 
$1 \quad 10^{\circ}$ intervals between 5 and $85^{\circ}$. The formulae follow Welles and Norman (1991), but

5 and

$6 \cos \beta=\frac{\cos \alpha \cos \theta}{\sin \alpha \sin \theta}$

$G_{\alpha}(\theta)=\cos \alpha \cos \theta$
[Eq. 8]
$11 G_{i}=\sum_{j=1}^{9} G_{i j} f_{j}$

$$
G_{i}=\sum_{j=1}^{9} G_{i j} f_{j}
$$
desirable. using a correction applied to the second equation (J. Welles, pers. comm.). Thus:

$$
(\text { for } \alpha+\theta \leq \pi / 2)
$$

$G_{\alpha}(\theta)=\frac{2}{\pi} \sin \theta \sin \alpha \sin \beta+\left(1-2 \frac{\beta}{\pi}\right) \cos \theta \cos \alpha \quad($ for $\alpha+\theta \geq \pi / 2)$

$G_{i}$ values, which provide a measure of the fraction of foliage projected in the direction of the five zenith angles, were calculated by summing the product of $G_{i j}$, the fraction of foliage in leaf inclination angle class $j$ projected in direction $i$, and $f_{j}$, the fraction of leaves in leaf inclination angle class $j$, as follows:

\section{Estimation of leaf area from measurements which included the contribution of branch} surface area was achieved in the present study by empirical calibration. Lang (1991) advocated that directly measured surface areas of branches should be subtracted from indirect estimates to obtain leaf surface area. However, this method is unsuitable for isolated canopies, for which the sensor position affects the proportion of branch area projected in the direction of the sensor, as branches are generally inclined upwards and outwards from the main stem. Thus, if the sensor is positioned adjacent to the stem, as suggested by Li-Cor (1992), the branch surface area projected in the direction of the sensor will be smaller than if the sensor is placed at the edge of the canopy. Therefore, although empirical calibration may appear less attractive than a fully mechanistic approach, the lack of appropriate theory to account for branches makes calibration 


\section{Canopy analyser measurements}

A $90^{\circ}$ view cap was used to restrict the azimuthal range of the sensor. Measurements were made at $1 \mathrm{~m}$ intervals to the north and south of trees 5 to 10 within two replicate plots for each species, providing 20 measurements per species. An effort was made to include the entire range of leaf area densities present in each dataset by subjectively selecting two $5 \mathrm{~m}$ row sections for each species with relatively low and high leaf area densities. Individual 'above canopy' measurements made $10 \mathrm{~m}$ from the tree rows were followed in close succession by a series of five measurements beneath the canopy at adjacent points along the row. The sensor head was levelled using the integral spirit level and directed with the aid of a compass towards the north or south azimuth for all above and below canopy measurements. Practical problems were encountered with the rapid failure of light following sunset at equatorial latitudes and the lack of overcast days during some seasons which limited the opportunity to make measurements under diffuse radiation conditions. Data were downloaded onto a PC and subsequent calculations performed using a spreadsheet. Dimensions to define the ellipse for path length and canopy volume calculations were taken as the averages of three sets of canopy measurements made at the sensor measurement position, and at distances of 50 $\mathrm{cm}$ to either side. These comprised the top and bottom heights of the canopy and distance to the edge of the canopy from the centre of the tree row (Fig. 1). M. volkensii canopies averaged $6.6 \pm 0.18 \mathrm{~m}$ width and $5.1 \pm 0.13 \mathrm{~m}$ depth and $\underline{\mathrm{C}}$. megalocarpus canopies $5.7 \pm 0.09 \mathrm{~m}$ width and $3.0 \pm 0.08 \mathrm{~m}$ depth. Both canopies of both species were, to a first approximation, elliptical in cross section although those of C. megalocarpus tended to broaden with height.

\section{Direct measurement of leaf area}

Leaf area was measured immediately after completing LAI-2000 measurements. Due to the practical difficulty of stripping leaves from trees and calculating the volume of canopy sections with complex profiles, it was assumed that the leaf area density of the volume viewed by the canopy analyser corresponded to a $1 \mathrm{~m}$ wide section oriented perpendicular to the tree row and centred on the measurement point. Leaf area was determined by measuring the dry weight of leaves removed from the canopy section 
1 and multiplying the values obtained by the corresponding specific leaf area determined 2 for sub-samples with the aid of an ADC LA-2000 leaf area meter (Analytical 3 Development Company, Hoddesden, Herts). Leaf area density was obtained by 4 dividing leaf area by the estimated volume of the canopy section from which the leaves 5 were removed.

6 


\section{RESULTS AND DISCUSSION}

\section{Leaf inclination}

Mean leaf inclination was calculated from LAI-2000 output using both of the methods for estimating path length described above. Norman and Welles (1983) suggested that constraints should be applied for extreme leaf angles due to uncertainties in the empirical relationship used to relate radiation measurements to leaf angle. The first method, with path lengths equal to $1 / \cos \theta$ produced out-of-range values (i.e. $>90^{\circ}$ or $\left.<0^{\circ}\right)$ in 39 out of 40 cases. This was to some extent expected as actual path lengths differed systematically from the theoretical lengths for horizontally continuous canopies, leading to errors in the contact frequencies (Ki) used to calculate mean leaf inclination (Li-Cor, 1992). For the second method, in which estimated path lengths were used, $60 \%$ of values were within range for $\underline{M}$. volkensii (mean leaf inclination $\left.50.0 \pm 4.42^{\circ}\right)$ and $95 \%$ for C. megalocarpus $\left(58.2 \pm 2.94^{\circ}\right)$. The out-of-range values were partly attributable the small, non-horizontally homogeneous canopies of the trees, which violated the implicit assumption in substituting $K$ from equation 2 into equation 5 that leaf angle distribution, represented by $G(\theta)$, and $\mu$ are constant, and that contact frequency, $K$, is affected only by changes in zenith angle. In reality, leaf angle distribution and $\mu$ are often not constant in isolated canopies as leaf area density and/or leaf angle may be greatest at the edges of the canopy. When out-of-range values were excluded, Kruskal-Wallace tests showed that mean leaf inclination angles did not differ significantly from directly measured values for either $\underline{M}$. volkensii $(p=0.70)$ or $\underline{C}$. megalocarpus $(\mathrm{p}=0.61)$.

Mean leaf inclination angles derived from direct measurements were greater in $\underline{\mathrm{C}}$. $\underline{\text { megalocarpus }}\left(60.3 \pm 1.30^{\circ}\right)$ than in $\underline{\mathrm{M}}$. volkensii $\left(51.1 \pm 3.33^{\circ} ; \mathrm{p}<0.01\right)$. Measured leaf inclination angles showed a greater frequency of more steeply inclined leaves in the former species (Fig. 2). Spherical leaf angle distribution is also shown for comparison, where the frequency of leaves in the $\mathrm{n}^{\text {th }}$ leaf angle class is given by:

$f(n)=\cos ((n-1) \delta)-\cos (n \delta)$ 
and $\delta$ denotes class width in degrees. G-tests (Sokal and Rohlf, 1998) showed that direct measurements of leaf angle distribution using class widths of $5^{\circ}$ differed significantly from the spherical distribution in $\underline{\mathrm{C}}$. megalocarpus ( $\mathrm{p}<0.01$ ), but not in $\underline{\mathrm{M}}$. volkensii $(\mathrm{p}=0.18)$.

The smaller $G_{i}$ values obtained at higher zenith angles in $\underline{\mathrm{M}}$. volkensii meant that the conventional assumption of a spherical leaf angle distribution for missing measurement rings resulted in overestimation of leaf area density. The opposite was true for $\underline{\mathrm{C}}$. megalocarpus, for which $G_{i}$ was larger at higher zenith angles. Within the c. 300 measurements made for each species, outer ring measurement values were missing on 59 and $71 \%$ of occasions for $\underline{\mathrm{C}}$. megalocarpus and $\underline{\mathrm{M}}$. volkensii respectively. With one ring missing, the differences in leaf area density resulting from use of spherical rather than measured leaf angle distributions was $3.9 \%$ for $\underline{\mathrm{C}}$. megalocarpus and $-0.4 \%$ for $\underline{\mathrm{M}}$. volkensii, rising to 11.1 and $-7.7 \%$, respectively, with three rings missing. Directly measured distributions were therefore used to calculate $G_{i}$ in Eq. 7 when values for one or more of the outer LAI-2000 measurement rings were missing.

\section{Leaf area}

Regression of results from Method 1 against direct measurements of leaf area density (LAD; Table 1, Figs. 3a and 4a) provided much poorer fits and larger underestimates than Method 2 (Table 1, Figs. 3b and 4b). The underestimation provided by Method 1 resulted from the inappropriateness of the theory for small canopies that did not fill the view of the canopy analyser. The slope of the regression did not differ significantly from zero for $\underline{\mathrm{C}}$. megalocarpus ( $\mathrm{p}=0.12$ ), partly due to two outlying points with particularly high measured values, but was significant for $\underline{\text { M. }}$ volkensii $(\mathrm{p}<0.01)$ despite similar underestimates of LAD at high leaf area density. Method 1 was therefore considered inappropriate for small canopies.

Figures $3 \mathrm{~b}$ and $4 \mathrm{~b}$ show the relationships between measured and estimated values of LAD obtained using Method 2. On average, LAD was overestimated by $8.4 \%$ in $\underline{\mathrm{C}}$. megalocarpus and underestimated by $15.7 \%$ in $\underline{\mathrm{M}}$. volkensii. The slopes of the regression lines were significantly less than 1 for both $\underline{\mathrm{C}}$. megalocarpus $(\mathrm{p}=0.043)$ and 
$1 \quad$ M. volkensii $(\mathrm{p}<0.001)$. This effect was probably attributable either to leaf clumping, a common cause of underestimation when leaf area is determined using indirect methods (Cohen et al., 1995; Hanan and Bégué, 1995; Levy and Jarvis, 1999), or to light scattering within their canopies (Macfarlane et al., 2000). However, observations suggested that the lower regression slope for $\underline{\mathrm{M}}$. volkensii resulted from clumping of leaves around terminal nodes. In $\underline{C}$. megalocarpus leaves were more evenly distributed along closely spaced branches.

Intercepts with the $y$-axis were positive and differed significantly from zero $(\mathrm{p}=0.05$; Table 1), indicating that the presence of non-leafy plant material such as branches and trunks caused LAD to be overestimated at low measured values. The much larger positive intercept for $\underline{\mathrm{C}}$. megalocarpus reflects the greater proportion of branch surface area within its smaller, denser canopy. At higher LADs, where the effect of non-leaf surface area is reduced (Smolander and Stenberg, 1996), estimated and measured values corresponded more closely $( \pm 10 \%)$. By contrast, leaf areas in $\underline{M}$. volkensii were underestimated, particularly at higher LAD values, probably due to the more clumped nature of its canopy. This may be further explained by increases in canopy clumping as leaf area index increases, as reported for apple trees by Cohen et al. (1995).

The wider scatter around the regression line for $\underline{\mathrm{M}}$. volkensii resulted partly from within-row variation in leaf area as direct measurements showed that mean coefficients of variation within tree rows were $41 \%$ greater than in $\underline{C}$. megalocarpus. The greater influence of branch surface area on radiation transmission associated with the lower LAD values for $\underline{\mathrm{M}}$. volkensii may also have increased errors, as reported for sparse eucalypt canopies (Whitford et $\underline{\text { al. }}$, 1995).

Although no measurements were made, it is possible that the leaves of both species were not randomly distributed with respect to the azimuth. If this was the case, bias may have resulted because the LAI-2000 sensor was directed outwards from the centre of the canopy. Leaves facing away from the axis of the tree rows, as found in orange tree hedgerows in Israel (Cohen and Fuchs, 1986), would result in overestimation of leaf area. Additional measurements made parallel to the axis of the rows would be necessary to avoid such errors. Such measurements were not made in the present study 
because the close spacing of the trees meant that trunks and large branches dominated the field of view of the canopy analyser.

As residuals from the regression analysis showed no apparent skewing, it was concluded that no obvious relationships in the data obtained remained unaccounted for in either species. The random variation was of little importance given the repetition of the measurements to estimate leaf area for individual tree rows. Method 2 was therefore used in conjunction with the calibration to assess the leaf area of trees throughout the measurement campaign.

Variation in measurement techniques renders comparison with results obtained by other workers difficult. The LAI-2000 has not been used extensively with isolated canopies in previous studies and its use with isolated tree rows has not been documented. The results obtained for $\underline{\mathrm{M}}$. volkensii at higher leaf area densities are consistent with the isolated tree technique used for Acacia koa by Grace and Fownes (1998), in which leaf area was also underestimated. However, Brenner et al. (1995) found that the LAI-2000 overestimated the total surface area of isolated Retama sphaerocarpa bushes by c. 14\%; the discrepancy was attributed to errors in the estimation of path length.

\section{CONCLUSIONS}

The significant correlations between measured leaf area density and estimated values obtained using directly estimated path lengths (Figs. $3 \mathrm{~b}$ and $4 \mathrm{~b}$ ) demonstrate that the theory initially described by Welles and Norman (1991) and further developed in the present study may be used reliably to calibrate LAI-2000 output for isolated tree rows. The particular success of the approach for $\underline{\mathrm{C}}$. megalocarpus reflected its greater canopy homogeneity in terms of leaf area and canopy dimensions relative to $\underline{\mathrm{M}}$. volkensii. The high leverage of the points representing the greatest leaf area densities for both species (Figs. $3 b$ and $4 b$ ) suggests that further confirmatory measurements would be desirable.

Measurement of the leaf area of isolated canopies is challenging and represents an extreme test of indirect methods. Although the method developed here involved some 
1 data manipulation to avoid the use of questionable assumptions, the time required 2 could be greatly reduced in future studies. The method reported here has potential for 3 use with isolated tree rows. In the absence of independent measurements of additional 4 canopy structural parameters, validation and/or calibration may be necessary. 


\section{ACKNOWLEDGMENTS}

2

3 JSB thanks the UK Natural Environment Research Council and ICRAF for financial 4 support in the form of a postgraduate scholarship. Thanks also to Anthony Muasa and 5 other staff at ICRAF's Machakos field station for assistance with measurements.

6 Additional technical and material support were provided by ICRAF and the Swedish 7 International Development Agency. 


\section{REFERENCES}

Anderson, M.C., 1966. Stand structure and light penetration. II. A Theoretical analysis. J. Appl. Ecol. 3, 41-54.

Brenner, A.J., 1996. Microclimate modifications in agroforestry. In: Ong, C.K., Huxley, P. (Eds.), Tree-Crop Interactions - A Physiological Approach, CAB International, Wallingford, Oxford, UK, pp. 159-187.

Brenner, A.J., Ceuto Romero, M., Garcia Haro, J., Gilabert, M.A., Incoll, L.D., Martinez Fernandez, J., Porter, E., Pugnaire, F.I., Younis, M.T., 1995. A comparison of direct and indirect methods for measuring leaf and surface areas of individual bushes. Plant, Cell \& Environ. 18, 1332-1340.

Broadhead, J.S., 2000. Ecophysiology of Indigenous Trees in Agroforestry Systems in the Semi-Arid Tropics. PhD Thesis, University of Nottingham. 259 pp.

Broadhead, J.S., Ong, C.K., Black, C.R., 2002a. Tree leafing phenology and crop growth in semi-arid agroforestry systems. Agric. Ecosys. Env. (submitted).

Broadhead, J.S., Ong, C.K., Black, C.R., 2002b. Tree phenology and water availability in semi-arid agroforestry systems. For. Ecol. Manage. (submitted).

Cohen, S., Fuchs, M., 1986. The distribution of leaf area, radiation, photosynthesis and transpiration in a shamouti orange hedgerow. II. Leaf area and radiation. Agric. For. Meteorol. 40, 123-144.

Cohen, S., Monsoni, P., Meron, M., 1995. Canopy clumpiness and radiation penetration in a young hedgerow orchard. Agric. For. Meteorol. 76, 185-200.

Grace, K.T., Fownes, J.H. (1998). Leaf area allometry and evaluation of nondestructive estimates of total leaf area and loss by browsing in a silvopastoral system. Agrofor. Syst., 40, 139-147. 
Hanan, N.P., Bégué, A., 1995. A method to estimate instantaneous and daily intercepted photosynthetically active radiation using a hemispherical sensor. Agric. For. Meteorol. 74, 155-168.

Howard, S.B., Ong, C.K., Rao, M.R., Muthuva, M., Black, C.R., 1995. Partitioning of light and water in leucaena-maize agroforestry systems. In: Sinoquet, H., Cruz, P. (Eds.), Ecophysiology of Tropical Intercropping, INRA Editions, Paris, pp. 123-135.

Jackson, J.E., Palmer, J.W., 1989. Light availability at the tree/crop interface. In: Reifsnyder, W.S., Darnhofer, T.O. (Eds.), Meteorology and Agroforestry, ICRAF, Nairobi, 546 p.

Lang, A.R.G., 1991. Application of some of Cauchy's theorems to estimation of surface areas of leaves, needles and branches of plants, and light transmittance. Agric. For. Meteorol. 55, 191-212.

Lang, A.R.G., Yueqin, X., Norman, J.M., 1985. Crop structure and penetration of sunlight. Agric. For. Meteorol. 35, 83-101.

Levy, P.E., Jarvis, P.G., 1999. Direct and indirect measurements of LAI in millet and fallow vegetation in HAPEX-Sahel. Agric. For. Meteorol. 97, 199-212.

Li-Cor, 1992. LAI-2000 Plant Canopy Analyser, Li-Cor, NE, USA.

Lott, J.E. Black, C.R., Ong, C.K., 2000. Allometric estimation of above-ground biomass and leaf area in managed Grevillea robusta agroforestry systems. Agrofor. Syst. 49, 1-15.

Macfarlane, C., Coote, M., White, D.A., Adams, M.A., 2000. Photographic exposure affects indirect estimation of leaf area in plantations of Eucalyptus globulus Labill. Agric. For. Meteorol. 100, 155-168.

Miller, J.B., 1967. A formula for average canopy density. Aust. J. Bot. 12, 141-144.

Monsi, M, Saeki, T., 1953. Über den Lichtfaktor in den Pflanzengesellschaften und seine Bedeutung für die Stoffproduktion. Jap. J. Bot. 14, 22-52. 
1 Norman, J.M., Campbell, G.S., 1989. Canopy structure. In: Pearcy, R.W., Eherlinger, J., Mooney, H.A., Rundell, P.W. (Eds.), Plant Physiological Ecology, Chapman and Hall, London, pp. 301-325.

Norman, J.M., Jarvis, P.G., 1975. Photosynthesis in Sitka spruce (Picea sitchensis (Bong.) Carr.). V. Radiation penetration theory and a test case. J. Appl. Ecol. $12,839-878$.

Norman, J.M., Welles, J.M., 1983. Radiative-transfer in an array of canopies. Agron. J. 75, 481-488.

Nygren, P., Rebottaro, S., Chavarria, R., 1994. Application of the pipe model-theory to non-destructive estimation of leaf biomass and leaf area of pruned agroforestry trees. Agrofor. Syst. 23, 63-77.

Ong, C.K., Corlett, J.E., Singh, R.P., Black, C.R., 1991. Above and below ground interactions in agroforestry systems. For. Ecol. Manage. 45, 45-47.

Ross, J., 1975. Radiative transfer in plant communities. In: Monteith, J.L. (Ed.) Vegetation and the Atmosphere: Volume 1, Principles. Academic Press, London pp. 13-55.

Smolander, H., Stenberg. P., 1996. Response of LAI-2000 estimates to changes in plant surface area index in a Scots Pine stand. Tree Physiol. 16, 345-349.

Sokal, R.R., Rohlf, F.J., 1998. Biometry (Third Edition), W.H. Freeman and Company, New York. 887 pp.

Tournebize, R., Sinoquet, H., 1995. Light interception and partitioning in a shrub/grass mixture. Agric. For. Meteorol. 72, 277-294.

Villalobos, F.J., Orgaz, F., Mateos, L., 1995. Non-destructive measurement of leaf area in olive (Olea europaea L.) trees using a gap inversion method. Agric. For. Meteorol. 73, 29-42.

Warren-Wilson, J., Reeve, J.E., 1959. Inclined point quadrats. New Phytol. 59, 1-8. 
1 Welles, J.M., 1990. Some indirect methods of investigating canopy structure. Remote Sensing Rev. 5, 31-43.

3 Welles, J.M., Norman, J.M., 1991. Instrument for indirect measurement of canopy architecture. Agron. J. 83, 818-825.

Whitford, K.R., Colquhoun, I.J., Lang, A.R.G., Harper, B.M., 1995. Measuring leaf area index in sparse eucalypt forest: a comparison of estimates from direct measurements, hemispherical photography, sunlight transmittance and allometric regression. Agric. For. Meteorol. 74, 237-249. 


\section{APPENDIX 1}

2 Derivation of formula to determine ray path length, $S$, through a tree canopy with an 3 elliptical cross section (cf. Fig. A1).

4 The position of $E$, the entry point of a notional ray with an angle $\theta$ from the vertical

5 (Fig. 1), is found in terms of $\alpha$ from the measured dimensions $p, a$ and $b . p$ is the 6 distance of the canopy analyser sensor below the centre of the canopy, while $a$ and $b$ 7 are defined by canopy dimensions.

8 The standard polar co-ordinates for an ellipse are:

$9 \quad x_{e}=a \cos \alpha$

$10 \quad y_{e}=b \sin \alpha$

Inspection of Figure A1 reveals the following relationship:

$x_{e}=p \tan \theta+y_{e} \tan \theta$

$14 \tan \theta=\frac{a \cos \alpha}{b \sin \alpha+p}$

Squaring both sides and using De Moivre's theorem gives:

17 which on solving for alpha gives:

$18 \alpha=\sin ^{-1}\left(\frac{-p b \tan ^{2} \theta \pm a\left(a^{2}+\tan ^{2} \theta\left(b^{2}-p^{2}\right)\right)^{1 / 2}}{a^{2}+b^{2} \tan ^{2} \theta}\right)$

Both positive and negative solutions give the correct path length, although the latter value is negative quantity. 
1 To determine $S$ from $\beta$ and $E, E$, defined as the Cartesian origin, is related to ellipsoid 2 co-ordinates $x^{\prime}$ and $y^{\prime}$ by:

$3 \quad x^{\prime}-x_{e}=x$

$4 \quad y^{\prime}-y_{e}=y$

5 The straight line, $D$, has an intercept equal to zero as the line is defined as passing

6 through the Cartesian origin, therefore:

$7 \quad y=\tan \beta x$

8 The general equation for an ellipse is:

$9 \quad \frac{x^{2}}{a^{2}}+\frac{y^{2}}{b^{2}}=1$

10 and for this ellipse:

$11 \quad \frac{x^{/ 2}}{a^{2}}+\frac{y^{/ 2}}{b^{2}}=1$

12 Substituting for $x^{\prime}$ and $y^{\prime}$ and combining with A9 gives:

$13\left(\frac{x+x_{e}}{a}\right)^{2}+\left(\frac{\tan \beta x+y_{e}}{b}\right)^{2}=1$

14 The solutions to this quadratic are 0 and

$15 x=\frac{-\left(b^{2} 2 x_{e}+a^{2} 2 y_{e} \tan \beta\right)}{\left(b^{2}+a^{2} \tan ^{2} \beta\right)}$

16 therefore, from equation A9

$17 y=\tan \beta\left(\frac{-\left(b^{2} 2 x_{e}+a^{2} 2 y_{e} \tan \beta\right)}{\left(b^{2}+a^{2} \tan ^{2} \beta\right)}\right)$

18 which by Pythagoras' theorem gives: 
$1 \quad S=\frac{2 a b(b \cos \alpha+a \sin \alpha \tan \beta)}{\cos \beta\left(b^{2}+a^{2} \tan ^{2} \beta\right)}$

2

3 
Figure 1. Schematic cross-section of tree canopy showing the five spatial regions of diffuse radiation interception corresponding to the light detecting rings 1-5 centred on zeniths of $7,23,38,53$ and $68^{\circ}$ as measured by the LAI-2000 canopy analyser. Dimensions recorded at $50 \mathrm{~cm}$ intervals along the tree row to allow estimation of path length and canopy volume for the defined ellipse are also shown.

Figure 2. Measured leaf angle distributions for $\underline{\mathrm{M}}$. volkensii and $\underline{\mathrm{C}}$. megalocarpus, and the theoretical spherical function, where inclination angle represents elevation above the horizontal.

Figure 3. Leaf area density (LAD) estimated from LAI-2000 canopy analyser measurements using (a) $1 / \cos \theta$ path lengths (Method 1) and (b) estimated path lengths (Method 2) plotted against directly measured values for $\underline{\mathrm{C}}$. megalocarpus. Solid lines show linear regressions fitted to the data; dashed lines show the 1:1 relationship.

Figure 4. Leaf area density (LAD) estimated from LAI-2000 canopy analyser measurements using (a) $1 / \cos \theta$ path lengths (Method 1) and (b) estimated path lengths (Method 2) plotted against directly measured values for $\underline{\mathrm{M}}$. volkensii. Solid lines show linear regressions fitted to the data; dashed lines show the 1:1 relationship.

Figure A1. Ellipse defined from canopy measurements to calculate path length, $S$, where $D$ represents a notional ray (short dashes), $E$ is the entry point the ray into the canopy, $F$ is the exit point of the ray from the canopy, $P$ is the distance between sensor and centre of canopy, $a$ is the ellipse semi-axis length (distance of the canopy edge from the tree row), $b$ is the ellipse semi-axis length ( 0.5 (canopy top height - canopy bottom height)), $\theta$ is the zenith angle (ring view angle), $\beta=90^{\circ}-\theta, \alpha$ is the angle between the horizontal at canopy centre and $\mathrm{E}$, and $x_{\mathrm{e}}$ and $y_{\mathrm{e}}$ are coordinates relating $E$, the Cartesian origin, to the ellipsoid origin $x^{\prime}, y^{\prime}$. Solid arrow heads represent dimensions taken from tree measurements; open arrow heads represent calculated dimensions. 
1 Table 1. Regression statistics for leaf area density (LAD) estimated using the LAI22000 canopy analyser using $1 / \cos \theta$ path lengths (Method 1), estimated path lengths

3 (Method 2) and measured directly for $\underline{\mathrm{C}}$. megalocarpus and $\underline{\mathrm{M}}$. volkensii.

\begin{tabular}{|c|c|c|c|c|c|c|}
\hline & $\begin{array}{c}\text { Response } \\
\text { variate }\end{array}$ & $\begin{array}{l}\text { Explanatory } \\
\text { variate }\end{array}$ & Slope $\pm \mathrm{se}^{*}$ & Intercept \pm se & $\mathrm{r}^{2}$ & $n$ \\
\hline \multicolumn{7}{|l|}{ Method 1} \\
\hline C. megalocarpus & $\begin{array}{l}\text { Estimated } \\
\text { LAD }\end{array}$ & $\begin{array}{l}\text { Measured } \\
\text { LAD }\end{array}$ & $\begin{array}{c}0.12 \pm 0.075 \\
(p=0.121)\end{array}$ & $\begin{array}{l}1.39 \pm 0.22 \\
(p<0.001)\end{array}$ & 0.13 & 20 \\
\hline$\underline{\text { M. volkensii }}$ & $\begin{array}{l}\text { Estimated } \\
\text { LAD }\end{array}$ & $\begin{array}{l}\text { Measured } \\
\text { LAD }\end{array}$ & $\begin{array}{l}0.22 \pm 0.07 \\
(p=0.008)\end{array}$ & $\begin{array}{c}0.209 \pm 0.05 \\
(p<0.001)\end{array}$ & 0.33 & 20 \\
\hline \multicolumn{7}{|l|}{ Method 2} \\
\hline C. megalocarpus & $\begin{array}{l}\text { Estimated } \\
\text { LAD }\end{array}$ & $\begin{array}{l}\text { Measured } \\
\text { LAD }\end{array}$ & $\begin{array}{c}0.83 \pm 0.080 \\
(p<0.001)\end{array}$ & $\begin{array}{c}0.70 \pm 0.024 \\
(p=0.009)\end{array}$ & 0.85 & 20 \\
\hline$\underline{\text { M. }}$ volkensii & $\begin{array}{l}\text { Estimated } \\
\text { LAD }\end{array}$ & $\begin{array}{l}\text { Measured } \\
\text { LAD }\end{array}$ & $\begin{array}{c}0.63 \pm 0.092 \\
(p<0.001)\end{array}$ & $\begin{array}{c}0.13 \pm 0.063 \\
\quad(p=0.05)\end{array}$ & 0.72 & 20 \\
\hline
\end{tabular}

4 *-P values indicate significance of slope difference from zero. 


\subsubsection{Broadhead et al Figure 1}

2

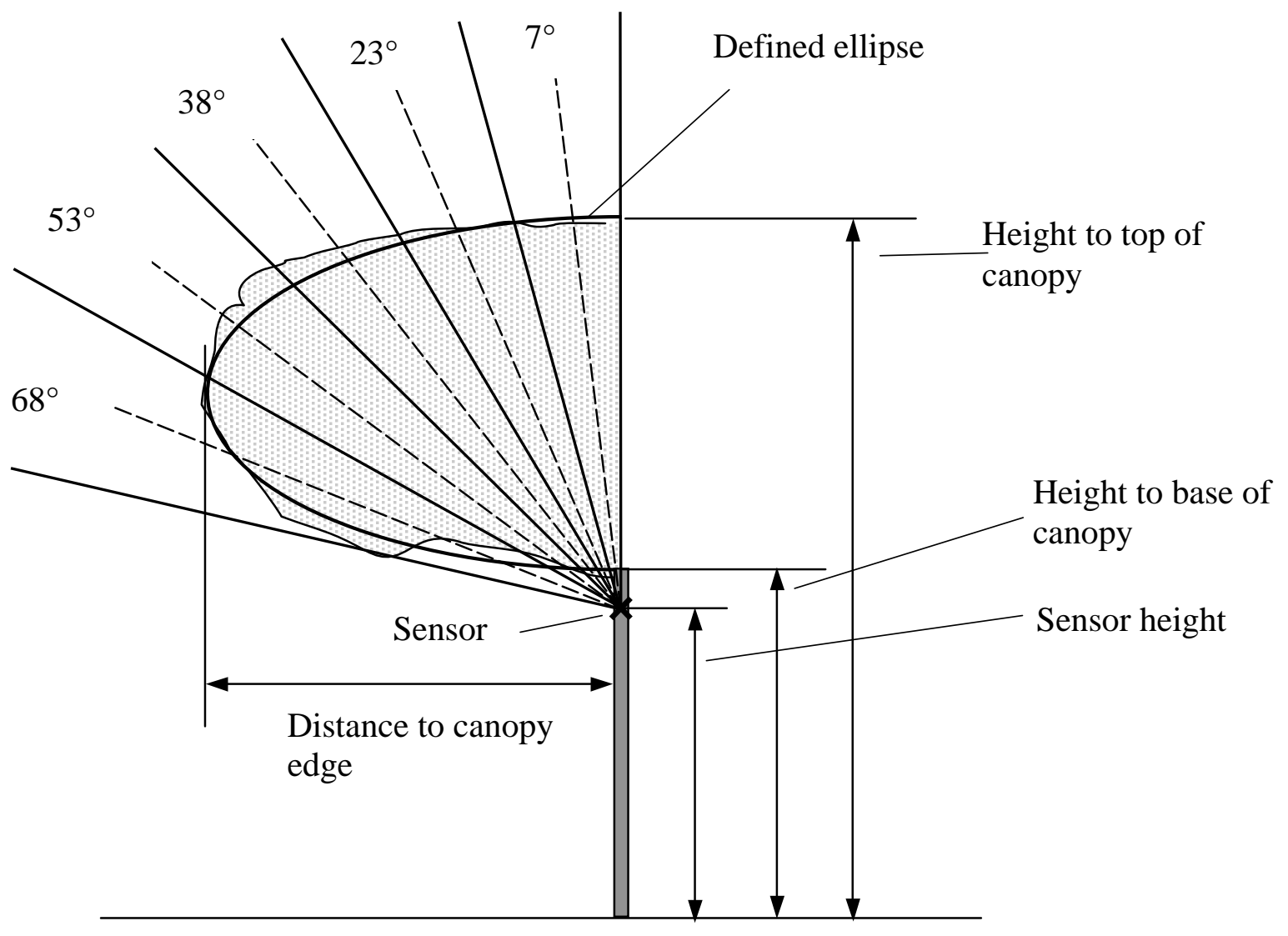




\section{Broadhead et al Figure 2}

2

5




$2 \quad$ 1.1.1.2 Broadhead et al Figure 3

3
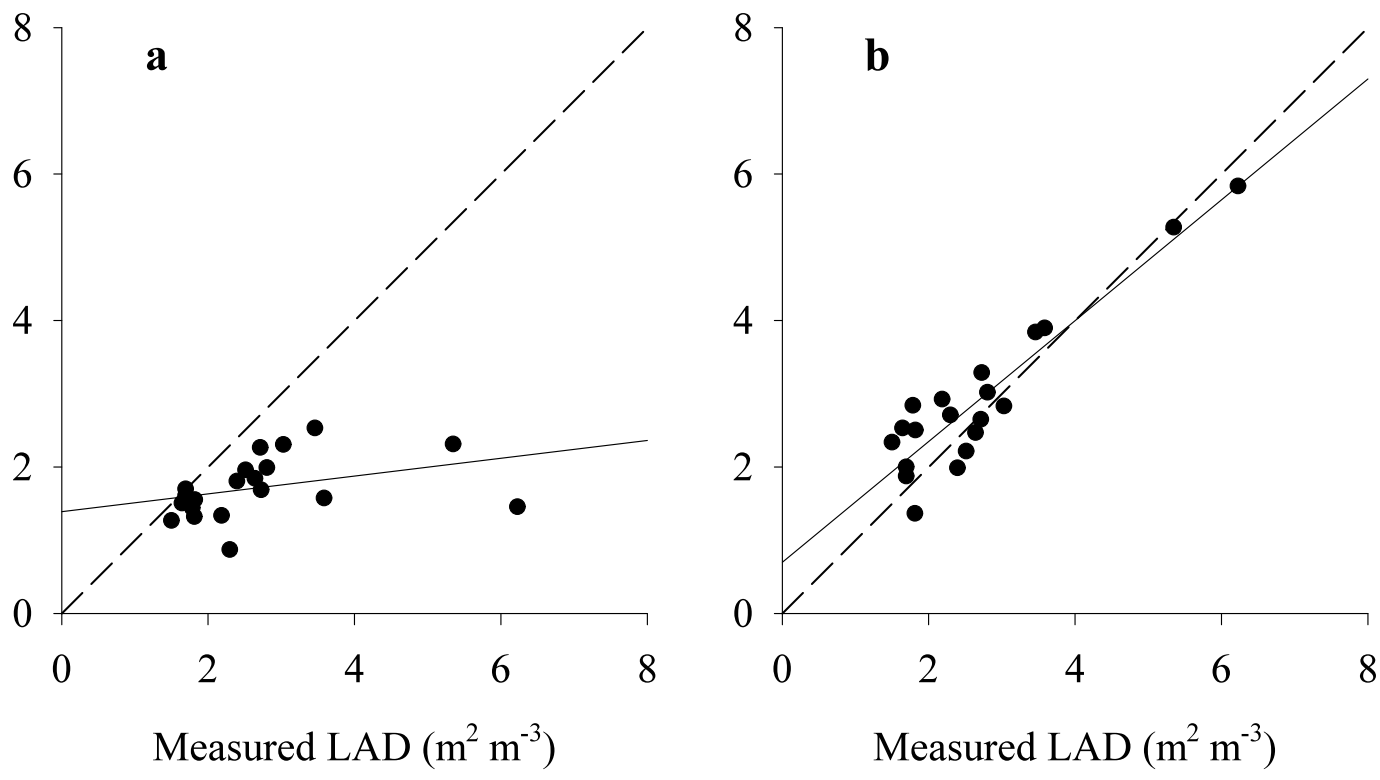

4

9

10

11

12

13

14 


\subsubsection{Broadhead et al Figure 4}

2

3


4

5

6

7

8 


\section{Broadhead et al Figure A1}



